\title{
ZONA LIVRE DE ARBITRAGEM: BRASIL PARA O PRIMEIRO MUNDO
}

Luiz Carlos Barnabé de Almeida

Professor, Mestre em Administração, Doutorando em Direito Ambiental Internacional da Universidade Católica de Santos. Bolsista Instituição.

MaRdônIO dA Silva GIRÃO

Professor, Mestre em Direito Ambiental, Doutor em Direito Ambiental Internacional pela Universidade Católica de Santos.

\section{Resumo}

No século XXI, o conhecimento é o fator de produçáo determinante para o crescimento econômico, sendo ele originário das Universidades e dos Centros de Pesquisa. Este estoque de conhecimento, utilizado pelo empreendedor criativo e por investidores de longo prazo com elevadas poupanças, são os transformadores do conhecimento em inovaçáo. Sendo o Brasil um país de poupança irrisória, nossa capacidade de gerar inovação é quase nula. Para mudar do ciclo de economia subdesenvolvida para desenvolvida é necessário atrair a poupança internacional intensiva e de longo prazo. Mas esta poupança só transformará em investimentos diretos em nosso país se tiverem a garantia da "segurança jurídica”. A realidade brasileira é de uma grande lacuna de segurança jurídica do Estado, por falta de Instituições maduras e por falta de uma reforma jurídica, para modernizar esta ação. Nossa sugestão neste artigo e uma institucionalização de uma "Zona Livre de Arbitragem”, que seria implantada como modelo na Regiāo Metropolitana da Baixada Santista. Indicamos esta região pelo potencial econômico de ser a regiáo onde se localiza o maior porto do Brasil e pelo espaço territorial para transformar as matéria primas em bens de maior valor agregado pela inovação.

\section{Palavras-chave}

Arbitragem; Inovação; Academia; Direito positivo.

\section{Abstract}

In the twenty-first century, knowledge is the determining factor of production to economic growth, being originally from universities and research centers. This stock of knowledge, used by creative entrepreneur and long-term investors with high savings, are 
the transformers of knowledge in innovation. Since Brazil is a country of paltry savings, our ability to generate innovation is almost nil. To change the underdeveloped economy cycle is designed to attract necessary intensive and international long-term savings. But this saving only turn into direct investments in our country if it is satisfied the "legal certainty". The Brazilian reality is a great legal security gap state for lack of mature institutions and for lack of a legal reform to modernize this action. Our suggestion in this article and the institutionalization of a "free zone Arbitration", which would be implemented as a model in the Baixada Santista. We indicate this region by the economic potential to be the region where is the largest port in Brazil and the territorial space to transform the raw material into goods with higher added value through innovation.

\section{Key words}

Arbitration; Innovation; University; Positive law.

\section{Introdução}

Uma das condiçóes para o Brasil fazer a passagem para o primeiro Mundo é através da Institucionalização da "Zona Livre de Arbitragem" implantada na Região Metropolitana da Baixada Santista. Condição que pode atrair a Poupança Internacional da Inovação.

Esta institucionalização criará uma rede de proteção jurídica ao Capital Internacional e Nacional que se encontra no exterior, de investimento direto, contra a "insegurança jurídica” predominante na justiça de Estado no Brasil.

A escassez da Poupança Nacional e o desinteresse da Poupança Inteligente Internacional (geradora do Investimento Direto em Inovação), tem inviabilizado nossa passagem para o primeiro mundo, retardando a implantação de Instituiçóes (Universidades e Institutos de Pesquisa) geradoras do estoque de conhecimento, de empresas inovadoras e Instituiçóes Financeiras com financiamentos de longo prazo, que são fundamentais para transformar o conhecimento em lucro, ou seja, em inovação.

Neste contexto, a infraestrutura científica assume papel relevante, em particular para os países subdesenvolvido, cujo sistema nacional de inovação é considerado incompleto dado o estágio de desenvolvimento de suas economias e das suas instituições (SUZIGAN, ALBUQUERQUE, CAIRO, 2011, p.9).

A "Nova Teoria do Crescimento Econômico", que procura explicar porque um país é desenvolvido e outro é subdesenvolvido, e como um país subdesenvolvido faz sua passagem para o status de desenvolvido, e porque outros não conseguem fazer esta travessia indica que a chave desta mudança é o "estoque de conhecimento", fator de produção com características de ser ilimitados e acumulativos, o que os diferencia dos outros fatores que são limitados e de rendimentos decrescentes. 
Mesmo a Nova Teoria do Crescimento Econômico não explicando todas as variáveis que levam os países a serem desenvolvidos ou subdesenvolvidos, é hoje a que melhor explica estas diferenças.

A nova teoria do crescimento enfatiza a possível capacidade dos recursos humanos de inovar a uma velocidade que compense os rendimentos decrescentes. Assim, "a nova teoria do crescimento provavelmente corresponde melhor aos fatos do mundo atual do que outras teorias, mas isso não faz com que seja correta” (PARKIN, 2009, p. 566).

O objetivo desse artigo será o de abordar o novo conceito de Ciência Econômica, considerando a escola neo-institucionalista de Coase, North, Williamson e a escola neo -schumpeteriana de Romer, a escola da análise econômica do direito - AED também denominada law and economic de Ronald Coase e Guido Calabresi.

Nesse mesmo sentido, pretende-se analisar, segundo Nusdeo (2008, p. 19), que o Direito e a Economia se imbricam e se integram para formar um único campo de Estudo.

Para tanto, utilizar-se-a a Nova Teoria do Crescimento Econômico desenvolvida por Paul Romer, da Universidade de Stanford durante a década de 1980; as características da insegurança jurídica no Brasil de acordo com estudos de Armando Castelar Pinheiro em 2005, do Instituto Brasileiro de Ética Concorrencial - ETCO (2008).

Pretende-se, ainda, realizar uma proposta com base em segurança jurídica, utilizando-se da arbitragem, mediação e conciliação que é será uma condição para o crescimento e poupança inteligente, e essa só é transformada em investimento quando existem condições de produção em escala mundial e de sua distribuição em uma Zona Livre de arbitragem na Região Metropolitana da Baixada Santista, que por sua localização geoeconômica poderá ser a pista para take off do Brasil em direção ao primeiro mundo.

\section{0 Direito e a Economia}

A compreensão da integração destas duas ciências das relaçóes humanas que formam um único campo de estudo, é relevante para entender que o crescimento econômico depende da segurança jurídica.

Já, na origem etimológica grega da palavra economia, faz-se sentir a intercomplementaridade e interdependência destas duas ciências, como podemos atestar: economia = oikosnomos, oikos significa casa, no sentido amplo, ou seja, onde se localiza e sobrevive a família; e nomos que representa a diversidade de normas necessárias destinadas às famílias, para a produção e distribuição dos bens econômicos (NUSDEO,2008).

Mais do que íntima relação, trata-se na verdade, de uma profunda imbricação, pois os fatos econômicos são o que são e se apresentam de uma dada maneira em função direta de como se dá a organização ou normatização - nomos - a presidir a atividade desenvolvida 
na oikos ou num dado espaço físico ao qual ela possa se assimilar. E o nomos nada mais vem a ser do que normas ou regras, estas objeto da ciência do Direito.

Nesse sentido, Nusdeo (2008, p.29) nos ensina que: "Reciprocamente, quanto mais escassos os bens e aguçados os interesses sobre eles, maior a quantidade e diversidade de normas se fazem necessárias para o equilíbrio de tais interesses".

Ao focar o homem, a ciência econômica verifica que este tem necessidades das mais diversas e que se expandem e se modificam em velocidades infinitas, caracterizando-as como "ilimitadas". Entender as necessidades e como atendê-las é condição fundamental para o entendimento da ciência econômica e da ciência jurídica e o campo científico que ambas se solidarizam.

Martinez e Paraguay (2003) apud Pereira, et al. (2012), informam que na década de 1940, Maslow estruturou a Teoria da Hierarquia das Necessidades Humanas que, indica para o entendimento do que, porque, quando, onde e como atender as necessidades humanas ilimitadas. As necessidades humanas são passíveis de serem categorizadas e organizadas em cinco níveis ascendentes: a) fisiológicas - relacionadas à sobrevivência e à homeostase do organismo; b) de segurança - relacionadas à segurança tanto física como emocional, familiar e social; c) sociais ou associativas - representadas pelo desejo de interagir socialmente, ser estimado e aceito, de pertencer a um grupo, de ter amizades e de amor; d) de estima - diz respeito à necessidade do indivíduo em manter a autoestima e ter a estima de outros, de desenvolver sentimentos de confiança, valor, capacidade, poder, prestígio, de ser útil e necessário; e, e) de autorrealização - dizem respeito ao autodesenvolvimento e à tendência dos indivíduos em tornar reais os seus potenciais.

À medida que as primeiras necessidades básicas sejam satisfeitas, surgem necessidades dos níveis seguintes, até se chegar às mais elevadas. Porém, esta hierarquia não é rígida, necessidades mais elevadas podem surgir antes das mais básicas terem sido completamente satisfeitas, pois estes níveis podem ser interdependentes ou justapostos, avaliam Martinez e Paraguay (2003) apud Pereira, et al. (2012), referindo-se aos estudos de Maslow.

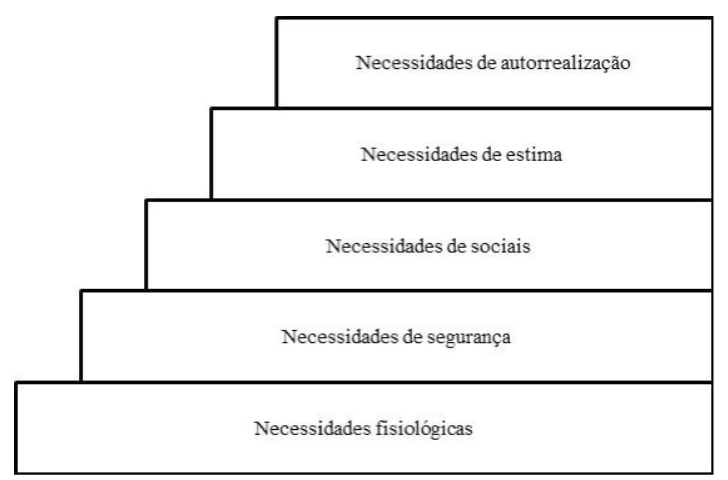

Figura 1: Pirâmide da Hierarquia das Necessidades Humanas, concebida por Maslow.

Fonte: Caravantes, Panno, Kloeckner (2005) apud Pereira, et al. (2012). 
A maneira de satisfazer estas diversas e hierárquicas necessidades ilimitadas são os "bens". Não existe outra maneira conhecida de atender as necessidades humanas senão os bens.

Quanto a natureza existem dois tipos de "bens", os bens livres e os bens econômicos.

Os bens livres são todos os tipos de bens encontrados no universo, que de forma natural, atendem as necessidades humanas, e que são "ilimitados" em função a estas. Como exemplo, a luz solar, ar e chuvas.

Já os bens econômicos são todos os tipos de bens que devem ser produzidos, os quais são pelos recursos produtivos, também chamados de fatores de produção.

Dessa forma, os fatores de produção são todos os recursos necessários para a produção do "bem econômico". Denominado de econômico por ser produzido, se não o fosse seria um "bem livre". Assim, os fatores de produção podem ser classificados pelo seu gênero, semelhança e outras características que indicam a mesma família.

Vale destacar que no novo conceito de Ciência Econômica, os recursos produtivos recebm outra classificação, ou seja, quanto ao capital humano, todos os homens e mulheres que poderiam produzir bens econômicos. As leis, culturas e costumes de cada grupo social, definem os "que podem" trabalhar. No Brasil essa população é quantificada pelo IBGE - Instituto Brasileiro de Geografia e Estatística, que denomina esta população produtiva de PIA - População em Idade Ativa subdividida em: PEA - População Economicamente Ativa e População Economicamente não Ativa (desempregados).

Ao considerar a questóes Patrimoniais (patrimônio da Nação), estas são divididas em Recursos Ecológicos ou Recursos Naturais (Bióticos e Abióticos), Ambientais (Externalidades Positivas e Negativas). Tecnologicos (saber fazer, saber produzir). Capital (infraestrutura, máquinas, equipamentos, plantas de produção e distribuição, portos, energia, saúde, educação). Instituições (Jurídicas, Legislativas, Executivas, Financeiras, Imprensa, Unidades de Produção e Distribuição, Unidades familiares e outras (neo-institucionalista)). Estoque de Conhecimento (condição para gerar a Inovação - fator neo-schumpeteriano).

Compete a Ciência Econômica através de leis e teorias criadas pelos modelos e dentro dos princípios de cada povo ou Nação, combinar os fatores de produção disponíveis com resiliência e utilizá-los plenamente, gerando assim sustentabilidade ambiental e social; transformando os fatores de produção de forma efetiva em bens econômicos e providenciando sua distribuição de forma equitativa, gerando um generalizado bem estar social do seu povo ou Nação.

Para que ocorra esta transformação em bens econômicos e sua distribuição, é necessário que existam Instituiçóes éticas, maduras e comprometidas com o bem-estar-social, através da estabilidade e contemporaneidade legislativa e executiva e a segurança jurídica, fundamentais para o aumento do estoque de conhecimento, que somado ao capital 
humano empreendedor e o capital intensivo de risco compóem a tríade geradora da "inovação", condição básica para o crescimen o econômico real de qualquer Nação.

A inovação está no cerne da mudança econômica, para Shumpeter (OCDE, 2005, p. 32-33) "Inovaçôes radicais provocam grandes mudanças no mundo, enquanto inovaçóes "incrementais" preenchem continuamente o processo de mudanças".

A interação dos fatores, para a produção e distribuição dos bens econômicos com objetivo de atender as necessidades ilimitadas, geram conflitos que deverão ser minimizados por normas jurídicas aplicadas por Instituiçôes maduras. Quanto mais eficiente e eficaz forem as Instituiçôes, menores serão os conflitos e maior e melhor serão a produçáo e a distribuiçẫo dos bens econômicos. Nesta fase, a Ciência Econômica "depende", "está em função", da Ciência Jurídica, que podemos representar pela representaçáo teórica: E = (f) D que se diz "A economia está em funçâo do Direito".

Os custos sociais, político e econômico das Instituiçôes servem para explicar porque um país é desenvolvido e outro subdesenvolvido. O prêmio Nobel de Economia em 1993, Douglas North, explica com propriedade científica a influência das Instituições no desenvolvimento de cada país... North cita o Brasil como exemplo de país que foi prejudicado pela falta de Instituiçóes que garantissem a segurança jurídica (ALMEIDA, 2012, p.308).

Como a maiorias dos fatores de produção são "limitados", a única exceção é o conhecimento ${ }_{2}$ e são os responsáveis para atender as necessidades que são "ilimitadas", denomina-se esta diferença de "escassez" que é a causa, origem do "conflito". O primeiro é de fundo econômico e o segundo jurídico, o que significa que quanto maior for a escassez maior será o conflito, neste caso a Ciência Jurídica depende, está em função da Ciência Econômica e podemos dizer então, através de uma representação teórica que o $\mathrm{D}=\mathrm{f}(\mathrm{E})$.

A "causa" é a escassez e o "efeito" o conflito. Para poder administrar o "efeito" tem que se conhecer a "causa" e esta é sempre econômica, razão pela qual o cientista jurídico deve conhecer os conceitos econômicos, e o cientista econômico os conceitos jurídicos (ALMEIDA, p. 101).

Esta interdependência, esta imbicação como afirma Nusdeo (2008, p. 29), comprova a importância da ciência jurídica para o crescimento econômico, principalmente na atual "economia baseada no conhecimento" que modificou o conceito de ciência econômica e da teoria do crescimento ampliando a dependência da "segurança jurídica".

A expressão "economia baseada no conhecimento" foi cunhada para descrever as tendências, verificadas nas economias mais avançadas, e a uma maior dependência de conhecimento informaçóes e altos níveis de competência e a uma crescente necessidade de pronto acesso a tudo isto (OCDE, 2005, p.31).

Nos capítulos seguintes iremos perceber a profundidade desta interdependência no mundo hodierno, onde a globalização mercadológica, ou seja, o tamanho do mercado é 
condição fundamental para o "lucro real" que é a remuneração do investimento intensivo em inovação.

A nova teoria econômica do crescimento econômico demonstra que o investimento é originário da poupança e esta é gerada em quantidade e rapidez pelo lucro real, que tem um ciclo de vida curto. Um novo lucro real só ocorrerá com uma nova inovação, acontecendo assim, o ciclo virtuoso da produção e distribuição em quantidade cada vez maior, atendendo uma maior quantidade de pessoas de nosso planeta e ampliando o "bem estar social mundial".

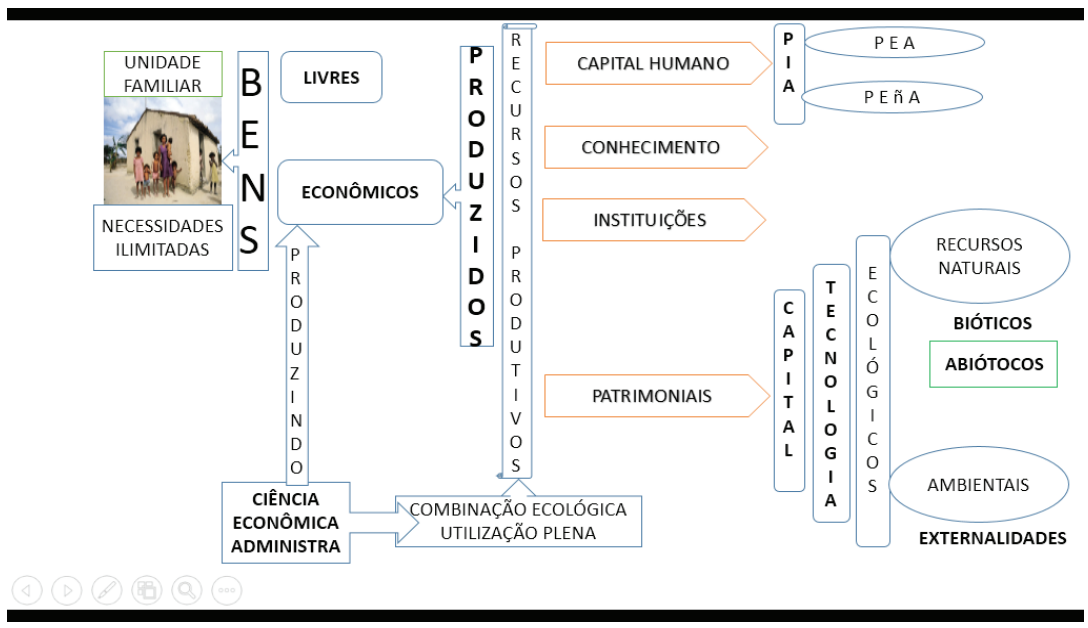

Figura 2. Representaçáo Gráfica do novo modelo de Conceito de Ciência Econômica.

Fonte: Almeida p. 67

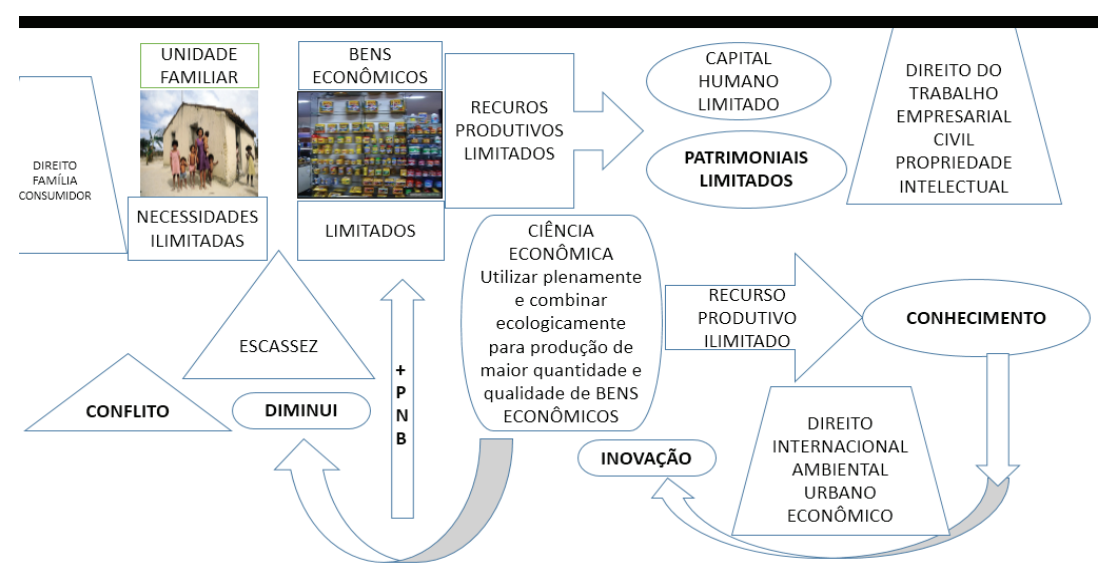

Figura 2.1 Representação Gráfica do novo modelo de Conceito de Ciência Econômica

Fonte: Almeida p. 67. 
Estas representaçóes gráficas do modelo do novo conceito da Ciência Econômica são autoexplicativas e demonstram o novo Conceito da Ciência Econômica que formula e aplica princípios, teorias, leis utilizando-se de modelos para melhor administrar os recursos produtivos limitados (exceção o conhecimento), por meio de uma perfeita combinação dos fatores com resiliência, obtendo assim uma maior quantidade e qualidade de bens econômicos, distribuição de forma equitativa, diminuição da escassez e do conflito, e melhoria do bem-estar social (ALMEIDA, p. 66).

Uma maior harmonia entre os fatores com mitigação dos conflitos impóe uma normatização aplicada pelas Ciências Jurídicas, quanto melhor e hodiernas forem as leis, maior será o crescimento econômico. Por exemplo, com leis trabalhistas justas, menores serão os conflitos deste fator de produção e maiores serão a eficiência e a produtividade, ou seja, maior quantidade e qualidade de bens econômicos serão produzidas. A interdependência destas duas ciências também é fundamental na distribuição equitativa destes bens.

\section{A Nova Teoria do Crescimento Econômico}

A Ciência Econômica explica os fenômenos econômicos através de leis e teorias. A teoria do Crescimento Econômico indica quais são os fatores que levam uma nação a ter um crescimento econômico maior que outras. Evidencia por que umas naçóes são desenvolvidas e outras subdesenvolvidas. Demonstra quais os fatores de produção e distribuiçáo que fizeram um país passar do estágio de subdesenvolvimento para o de um país desenvolvido. Informaçóes do Banco Mundial e do Fundo Monetário Internacional - FMI confirmam um fenômeno predominante no final do século XX até estas primeiras décadas do século XXI: as nações pobres ficam a cada ano mais pobres em relação as naçôes ricas, ou os países ricos ficam mais ricos em relação aos pobres. Assim, a distância entres eles fica cada vez maior.

O crescimento econômico é a expansão sustentada das possibilidades de produção medidas com o aumento do PIB real ao longo de um determinado período. Um rápido crescimento econômico mantido ao longo de vários anos pode transformar uma nação pobre em rica. Foi o que aconteceu com Hong Kong, Coréia do Sul, Taiwan e outras economias asiáticas. Um lento crescimento econômico ou ausência de crescimento pode condenar uma nação a uma pobreza devastadora. Este foi o destino de Serra Leoa, Somália e grande parte do resto da África. (PARKIN, 2009).

Em 2013, de acordo com dados do FMI, mais seis naçóes Africanas ampliariam o exemplo de Parkin (2009, p. 552), que são: Níger; Libéria; Burundi; Malavi; Congo, Dem. Rep.; República Centro-Africano.

É importante destacar que o valor do PIB de uma naçáo indica o poder econômico de uma em relaçáo a outra. Já o padrão de vida de cada povo depende do PIB real per capita (por pessoa), que é o PIB real dividido pela população da nação. $\mathrm{O}$ aumento do 
PIB real tem que ser em proporção maior que o aumento da população para que ocorra um aumento do padrão de vida de um povo.

Em 2013, o Fundo Monetário Internacional - FMI informou o PIB de 187 países. Para um melhor entendimento estes países foram divididos em sete grupos, na ordem decrescente e por tamanho do PIB real, iniciando o primeiro grupo com o símbolo (a) naçôes acima de US\$ 50,000 por pessoa; (b) de US\$ 49,999 até US\$ 35,000; (c) de US\$ 34,999 até US\$ 25,000; (d) de US\$24,999 até US\$10,000; (e) de US\$ 9,999 até US\$ 5,000; (f) de 4,999 até US\$ 2,000 e o último grupo de naçóes (g) abaixo de 1,999. A média mundial, ou seja, o PIB Mundial real, dividido pela população de nosso planeta foi de US\$14,307 dólares por pessoa. Veja quadro 1 abaixo.

Nesta classificação, entre os doze primeiros classificados, existem na realidade onze naçôes, pois Hong Kong, mesmo citado, pertence à China atualmente. Vejamos o Quadro do PIB real per capita por Grupo de 187 Naçóes e Hong Kong em 2013:

(a=\$50)-1 Catar 145.894-2 Luxemburgo 90.333-3 $\underline{\text { Cingapura }}$ 78.7624 - Brunei 73.823-5 $\underline{\text { Kuweit 70.785-6 }}$ Noruega 64.363-7 $=\underline{\text { Emirados }}$

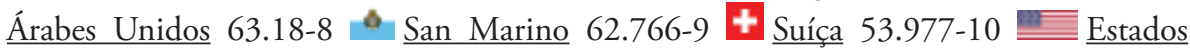
Unidos 53.001 औ Hong Kong $52.984-11$ Arábia Saudita 51.779

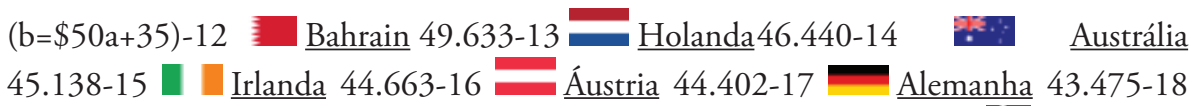

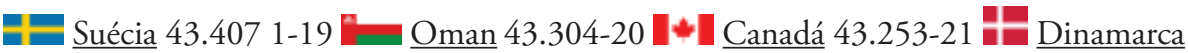

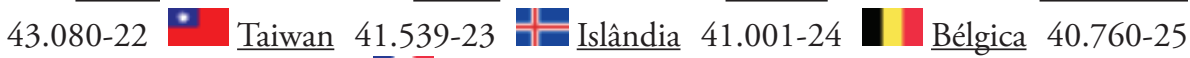

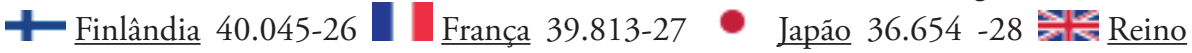
Unido 36.208

(c=\$35a+25)-29 Itália 34.103-30 " Coreia do Sul 33.791-31 uiné Equatorial 33.767-32 Nova Zelândia 33.626-33 Israel 32.717-34 Espanha 31.942-35 " Malta 30.567-36 Trinidad e Tobago 30.197-37 28.748-38 Eslovenia 28.512-39 República Checa 27.347-40 Eslováquia 26.616-41 Estônia 26.052-42 ${ }^{\circ}$ Portugal 25.643-43 Lituânia 25.374-44 Erécia 25.126

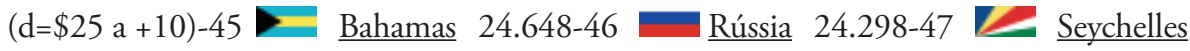
23.532-48 Polônia 23.273-49 Hungria 23.236-50 블 Mánia 23.160-51 


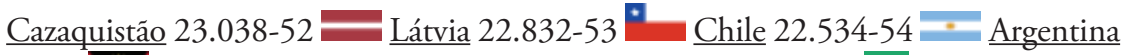

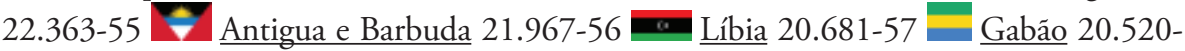
58 Croácia 20.222-59 São Cristóvão e Nevis 19.823-60 春 Uruguai 19.679-

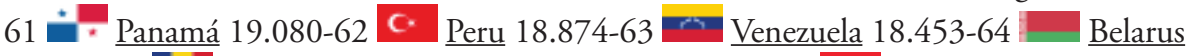

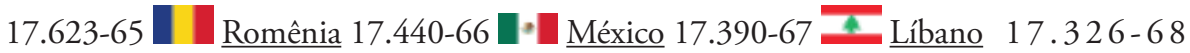

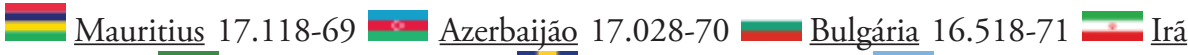
16.165-72 Suriname 16.080-73 $\Psi$ Barbados 16.015-74 Botswana 15.24175 Palau 15.005-76 $\theta$ Brasil 14.987-77 $\quad$ Montenegro 14.666-78 Iraque 14.367-79 Costa Rica 14.344-80 Tailândia 14.136-81 Argélia 13.788-82

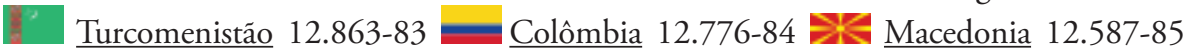

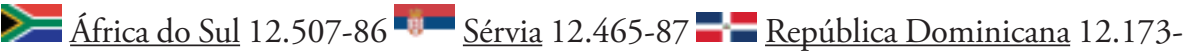

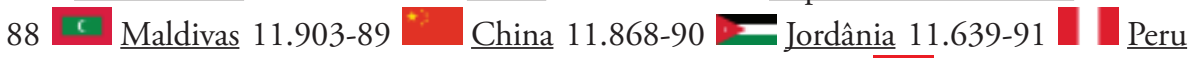
11.557-92 Grenada 11.481-93 ^ Santa Lúcia 11.150-94 @ Tunísia 10.998-95

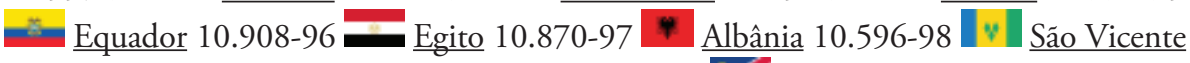
e Granadinas 10.560-99 E E

$(\mathrm{e}=\$ 10 \mathrm{a}+5)-101$ Indonésia 9.635-102 Herzegovina 9,563-104 í Mongólia 9,293-105 $\underline{\text { Kosovo 8.866-106 Ucrâ- }}$ nia 8,651-107 $\$ Lamaica 8,487-108

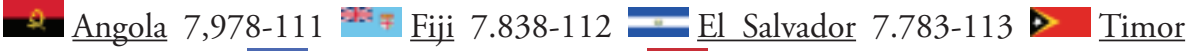
-Leste 7678-114 Suazilândia 7.646-115 Marrocos 7,356-116 미 Guate-

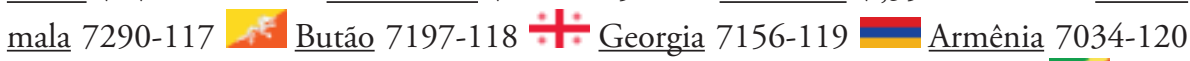
$>\underline{\text { Filipinas }} 6,597-121 \geq$ Guiana 6,573-122 를 Cabo Verde 6.248-123 go, Rep. 6232-124 Bolívia 5928-125 1 Nigéria 574-126 Índia 5.450-127

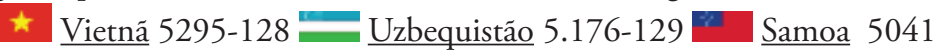

$(\mathrm{f}=\$ 5 \mathrm{a}+2)-130$ Tonga $4.856-131$ Moldova $4.666-132 \bullet \underline{\text { Laos }}$ 4.66-133

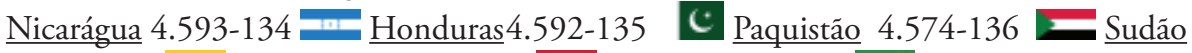

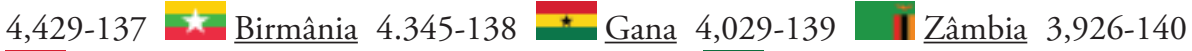
Iémen 3,838-141 Q Quirguistão 3,230-142 $\bullet$ Mauritânia 3187-143 ${ }^{\text {g: }}$ Tuvalu 3.168-144 Bangladesh 3.167-145 Ilhas Marshall 3.128-146 $\because \underline{\text { Mi- }}$

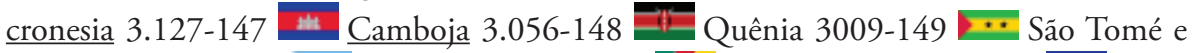
Príncipe 2.999-150 Djibouti 2,916-151 * Camaróes 2.861-152 Lesoto 2.765-153 Côted'Ivoire 2,710-154 Tajiquistão 2,536-155 Vanuatu 2.449-156 Chade 2.432-157 159 Nepal 2,245-160 * Senegal 2,243 
(g= -\$2)-161 Zimbábue 1.954-162 1.924-164 Tanzânia 1.834-165 Illhas Salomão 1.829 -166 Benin 1.793-

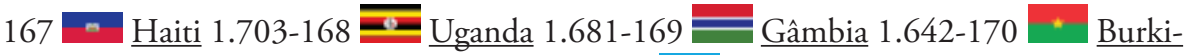

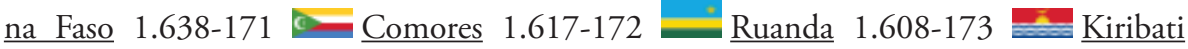
1.562 -174 Mali 1.493-175 토를 Etiópia 1.427-176 * Guiné-Bissau 1.411-177 Madagáscar 1.398-178 ${ }^{\star}$ Togo 1.390-179 Guiné 1321-180 D Eritrea 1.197-181 Noçambique 1.046-182 Níger 984-183 毫 Libéria 887-184 Burundi 877-185 Malavi 748-186 Congo, Dem. Rep. 655-187 트 República Centro-Africano 604

Figura 2.2: Quadro do PIB real per capita por Grupo de 187 Nações e Hong Kong em 2013:

Fonte: FMI (2013). Distribuição por grupo de Naçôes realizado pelos autores.

Ao compararmos as informaçóes de 2012 do Banco Mundial com as de 2013 do FMI podemos verificar mudanças pontuais que não iremos nos aprofundar neste artigo.

Ao demonstrar estas informaçóes queremos enfatizar a importância do aumento do Produto Interno Bruto PIB de cada nação, pois só desta maneira que existe uma melhora na qualidade de vida de cada povo, daí destacar este PIB por pessoa, pois de nada adianta o país ter um PIB maior que o outro, se ao dividi-lo pela sua populaçáo, o PIB per capita indica uma inferioridade muito grande da nação com PIB menor. Neste caso, tamanho do PIB não é vantagem para sua população.

Para ficarmos na América do Sul, verificamos que naçóes como Chile, Argentina, Uruguai, Peru, Venezuela, nesta ordem, têm um PIB por pessoa maior que a do Brasil em 2013, mesmo que o tamanho dos seus PIB's seja igual ou menor que alguns Estados brasileiros.

Aumentar o PIB per capita, significa aumentá-lo mais que proporcional o aumento da população, é a nova teoria do crescimento econômico que irá explicar por que isto acontece.

A nova teoria do crescimento sustenta que o PIB real per capita cresce devido às escolhas que as pessoas fazem em busca do lucro e que o crescimento pode persistir indefinidamente. Paul Romer, da Universidade de Stanford, desenvolveu essa teoria durante a década de 1980, mas as ideias básicas dela remontaram ao trabalho de Joseph Schumpeter durante as décadas de 1930 e 1940 (PARKIN, 2009 p.566).

Os grifos são dos autores, e demonstram uma nova forma de olhar para a produção dos bens econômicos, pois na teoria dos neoliberais, o crescimento não pode persistir indefinidamente, para eles existiam períodos que ocorriam uma interrupção do crescimento, sem saber explicar a razão deste fato. 
Fatores de produção como "conhecimento" e "Instituiçóes" não eram considerados, pois eles acreditavam que os homens tomavam açôes racionais, pensavam igual com ética e honestidade, não eram oportunistas e por sorte descobriam novas técnicas e produtos que geravam crescimento, mas acreditavam que este fato ocorria por acaso.

Mas no mundo real, os homens pensavam diferentes, tomavam muitas decisóes emocionais e muitos não eram nem éticos, nem honestos e em grande maioria oportunistas, daí a importância de Instituiçóes maduras para evitar ou diminuir os conflitos, que prejudicam a produção de bens, diminuindo o crescimento econômico. Esta nova corrente do pensamento econômico, os neo-institucionalistas (Coase, North Williamson e outros), foram fundamentais para respaldar a nova teoria do crescimento econômico (Paul Romer e outros neo-chumpeterianos), que utilizam dois fatos da "economia de mercado": a) as descobertas resultam de escolhas. b) as descobertas levam ao lucro, e a concorrência destrói o lucro.

Para entender a importância do lucro para o crescimento econômico real per capita, temos que afastarmos de antigas doutrinas econômicas de origem grega platônica (socialismo) ou aristotélica (intervencionismo), que viam o lucro (riqueza) como um mal em si mesmo.

A atitude filosófica conduz, enfim, ao desprezo da riqueza. Eis como o exprime Platão "O ouro e a virtude são como dois pesos colocados nos pratos de uma balança, de tal modo que um não pode subir sem que desça o outro".

A felicidade reside na virtude; a riqueza é um obstáculo à felicidade; logo, deve-se desistir de obtê-la (HUGON, 1995, p.32).

Assim, só ocorre o crescimento econômico real per capita quando as pessoas têm liberdade de escolhas e que suas descobertas são protegidas pela propriedade intelectual e material, através da "segurança jurídica" imposta pelo Estado de Direito, através das Instituiçôes maduras que protegem o Indivíduo de oportunistas, inclusive o Estado.

Voltando para a nova teoria do crescimento econômico, lembramos que esta teoria se fundamenta em dois fatos sobre a economia de mercado, primeiro as "descobertas e escolhas", não ocorrem por acaso, como acreditavam os neoliberais, mas pelas escolhas que as pessoas físicas ou jurídicas fazem. A quantidade e intensidade dessa busca irá determinar a velocidade das novas descobertas. Nesta escolha quantitativa e qualitativa dos fatores será determinada a intensidade das mudanças tecnológicas.

O lucro é o estímulo da mudança tecnológica. "As descobertas levam ao lucro e a concorrência destrói o lucro”.

Schumpeter usou a expressão "destruição criativa" pela primeira vez em 1942, para se referir à maneira como os produtos e métodos capitalistas inovadores estão constantemente tomando o lugar dos antigos (COSTA, 2012). 
Como as forças da concorrência diminuem o lucro, a maneira de sobreviver é manter o lucro real e para obtê-lo são necessárias permanentes buscas de novos métodos de produção de custos menores e melhores bens econômicos, em que os consumidores estarão dispostos a pagarem mais alto pela novidade. Ampliar o mercado de compradores é uma maneira de aumentar as vendas, diminuir os custos, diminuir os preços e aumentar os lucros.

Deve-se destacar que uma maneira de aumentar o lucro é vendendo bens econômicos para mais pessoas, este fato indica que o lucro contribui para que elas fiquem com suas necessidades atendidas, não importando onde morem, nem para o "lucro" nem para as "pessoas" que mesmo sendo de nacionalidades diferentes, têm necessidades iguais. Assim, a Globalização de mercado é uma maneira de aumentar o lucro real e atender as necessidades de uma maior quantidade de pessoas.

Mas como já tinha alertado Schumpeter (1997), os inovadores podem manter o lucro por vários anos, com registro de patentes ou direito autoral, no entanto, mais cedo ou mais tarde, uma nova descoberta cria um bem econômico semelhante e os lucros reais desaparecem.

Para a sua sobrevivência, uma empresa precisa de novos lucros reais e só vai obtê-los com novas invençôes, que levam a mais bens econômicos que irão atender mais necessidades humanas de maneira quantitativa e qualitativa.

Por maior que a necessidades humanas sejam atendidas, sempre haverá a escassez, porque sempre desejamos um padrão de vida mais alto. A escassez é o estímulo permanente para a sociedade buscar cada vez mais uma melhor e maior qualidade de vida.

$\mathrm{Na}$ busca de um padrão de vida mais alto, as sociedades humanas desenvolvem sistemas de incentivos - direitos de propriedade e trocas voluntárias nos mercados - que permitem às pessoas lucrar com a inovação.

A inovação leva ao desenvolvimento de novas técnicas de produção e novos e melhores produtos (PARKIN, 2009, p. 567).

A nova teoria do crescimento econômico continua explicando que, na busca de produzir novos bens econômicos (produtos e serviços), novas unidades de produção (empresas) serão implantadas, e muitas antigas encerrarão suas atividades, novas profissionalizaçóes serão criadas com melhor remuneração pela eficiência e eficácia que geram, enquanto outras profissóes deixarão de existir.

Novos e melhores empregos e produtos levam a mais bens e serviços de consumo e, combinados com mais lazer, levam a um padrão de vida superior. Entretanto nossas necessidades insaciáveis continuam presentes, de modo que o processo prossegue em círculos de necessidades, incentivos, inovaçóes e novos e melhores produtos e um padrão de vida cada vez mais alto (PARKIN, 2009, p. 568). 
Esta nova teoria destaca que os muitos tipos de conhecimento são um fator que nenhuma pessoa pode ser excluída, ainda mais que a utilização do conhecimento não impede a utilização por outras ao mesmo tempo, ou seja, desafia a lei da física, a da impermeabilidade, onde dois corpos não podem ocupar o mesmo lugar. Estas propriedades são denominadas pelos economistas de bens de capital público como, por exemplo, a justiça, tipos conhecimento.

Segundo OCDE (2008, p. 32-33) "é o transbordamento dos benefícios da inovação (externalidades positivas), o fato de que o retorno social da inovação é geralmente mais alto do que o retorno privado (clientes e concorrentes se beneficiam das inovaçóes de uma empresa)".

Outra importante indicação feita por esta teoria, e que a faz diferenciar-se de todas as outras desenvolvidas até então, é a observação que o fator conhecimento não está sujeito a rendimentos decrescentes. Os rendimentos decrescentes ocorrem na produção dos bens econômicos, quando um fator de produção é fixo (tamanho da fazenda de café) e outro fator de produção variável (adubo), a cada porção de adubo colocado na terra maior a produção de café até a uma determinada quantidade, depois a quantidade de adubo passa a ser prejudicial e a produção irá diminuir, este fato que os economistas chamam de rendimentos decrescentes. No caso do fator conhecimento, quanto "maior" faz com que os outros fatores de produção sejam mais produtivos de forma crescente e permanente. Não existe a interrupção do crescimento econômico quando se utiliza o fator de produção "conhecimento" geradora da "inovação".

Segundo Schumpeter (1997), as pesquisas que levam as descobertas e o conhecimento, quando transformados em novas atividades produtivas lucrativas são chamados de inovação. Como os geradores da inovação são públicos e ilimitados, a inovação também o é.

De acordo com Bresciani (2004, p.7), pode-se pensar em inovação do fator trabalho inovação do fator empresarial, inovação dos recursos naturais, inovação da tecnologia, inovação do capital, ainda inovação do processo de produção e serviços".

Deve-se salientar que após Schumpeter (1997) das décadas de 1930 e 1940, os economistas da década de 1980 em diante, conhecidos por neo- schumpeteriano ajustaram alguma de suas hipóteses como adaptaram esta teoria aos países subdesenvolvidos. Para os atuais economistas as novas pesquisas indicam que a inovação não é aleatória; ela surge de uma série de ações de busca, imitação e experimentação. Ela está no centro da sobrevivência e do crescimento das unidades de através da geração do lucro real, denominado por alguns economistas de lucro puro, que significa um lucro superior ao lucro de manutençáo, com objetivo de seu excedente ser aplicado em pesquisa para gerar novos conhecimentos, novas inovaçôes, novos lucros puros. Importante também a indicação feita pelos neo - schumpeteriano que o estímulo para inovação é originado tanto da demanda como da oferta. 
Sondando o mercado, o empresário verifica o que o público quer consumir e gera novos produtos, aperfeiçoa os existentes e adota processos mais eficientes. A partir de condiçóes internas de oferta, as tecnologias criam novas necessidades, induzindo a demanda de novos produtos, ou de produtos existentes ligeiramente modificados, ou de melhor qualidade (DORSI, 1988).

A boa notícia da nova teoria do crescimento econômico é que ela contradiz a teoria malthusiana que afirma o fim da qualidade de vida que temos hoje, ou seja, o fim da atual prosperidade que hoje vivenciamos. A nova teoria afirma que a prosperidade é ilimitada, não tem fim. Outra diferença entre as duas teoria é em relação ao aumento populacional, para os malthusianos este aumento é parte do problema do crescimento econômico por pessoa, já para os teóricos da nova economia não é problema, mas solução.

Uma população maior leva a mais necessidades, mas também a mais descobertas científicas e avanços tecnológicos. Assim, em vez de ser a fonte da redução do PIB real per capita, o crescimento populacional leva a um crescimento rápido da produtividade e um PIB real per capita crescente. Os recursos são limitados, mas a imaginação e a capacidade humana de aumentar a produtividade são ilimitadas (PARKIN, p. 586).

Considerando todos os estímulos para o crescimento econômico, ele só cresce com a poupança, responsável pelo investimento (aumento) dos fatores de produção ou recursos produtivos que foram descritos no início deste artigo como: capital humano, recursos patrimoniais, estoque de conhecimento e instituiçóes.

Com a mesma importância dada pelos Institucionalistas, Schumpeter considera como um novo fator de produção as instituiçóes eficientes. Enquanto os primeiros destacam as instituiçôes responsáveis pela segurança jurídica, o segundo as instituiçóes financeiras, fornecedoras de crédito e o meio social cultural progressista que estimulam a inovação.

Na visão de Souza (2009, p.132), o processo de produção Schumpeteriano envolve a combinação de forças produtivas formadas pelos fatores de produção capital $(\mathrm{K})$, pelo trabalho $(\mathrm{L})$, pelos recursos naturais $(\mathrm{N})$, pelas inovaçôes $(\mathrm{S})$ e pelas instituiçóes maduras (E). A função de produção especifica-se como: $\mathbf{Y}=\mathbf{f}(\mathbf{K}, \mathbf{N}, \mathbf{L}, \mathbf{S}, \mathbf{E})$.

As Fontes do Crescimento Econômico dependem do potencial dos recursos produtivos que podem ser indicados pela função agregada da produção que é representada pela fórmula $Y=f(K, N, L, S, E)$.

O crescimento econômico da produção de bens e serviços, que representa o mesmo valor do crescimento da renda agregada nacional decorre das variaçóes na quantidade e qualidade dos fatores (recursos) de produção como o $\mathbf{K}=$ Capital através do aumento no estoque de capital ou na capacidade produtiva; melhoria tecnológica, que aumenta a eficiência na utilização do estoque de capital; eficiência organizacional, ou seja, eficiência na alocação e combinação dos capitais. 
Em relação ao $\mathbf{N}=$ Recursos Naturais denominados atualmente ambientais através do aumento dos recursos naturais renováveis e da ecoeficientes na extração dos não renováveis.

O L = Trabalho denominado de Capital Humano através da melhoria da produtividade através da educação, especialização e treinamento e do Pleno emprego.

Quanto ao $\mathbf{S}$ = Estoque de Conhecimento através do aumento quantitativo e qualitativo das Instituiçóes de Educação Superior - IES’s e o aumento dos Institutos de Pesquisa;

E por fim, o E = Instituiçóes através do aumento das Instituições fundamentadas pela busca da inovação; aumento quantitativo e qualitativo das Instituiçóes Jurídicas, e o aumento quantitativo e qualitativo nas Instituições socioculturais progressistas.

A complexa combinação e utilização plena dos fatores acima descritos é que irão ser responsáveis por toda produção nacional, ou seja, pelo Produto Interno Bruto - PIB que representa tudo que foi produzido dentro da Nação, ou por empresas nacionais ou estrangeiras localizadas no território Nacional. O valor monetário (geralmente dólar) que representa este PIB é o mesmo valor da Renda Bruta. Tudo que é produzidos pelas Unidades de Produção irão gerar bens econômicos que seus valores monetários serão igual aos valores monetários da rendas recebidas pelas Unidades Familiares. O aumento do PIB representa o aumento quantitativo e qualitativo destes fatores de produção.

Esta complexidade que leva ao aumento da produçáo cria uma variedade de conflitos que devem ser administradas para serem minoradas, facilitando o aumento sustentável do PIB, daí pode-se imaginar a importância de Instituiçóes Jurídicas na gestão da segurança jurídica para todos os agentes econômicos envolvidos no aumento da produção e distribuição dos bens econômicos.

FATORES dE PROdUçÃo. ATITUdES E PROCESSOS PARA O AUMENTO dO PIB.

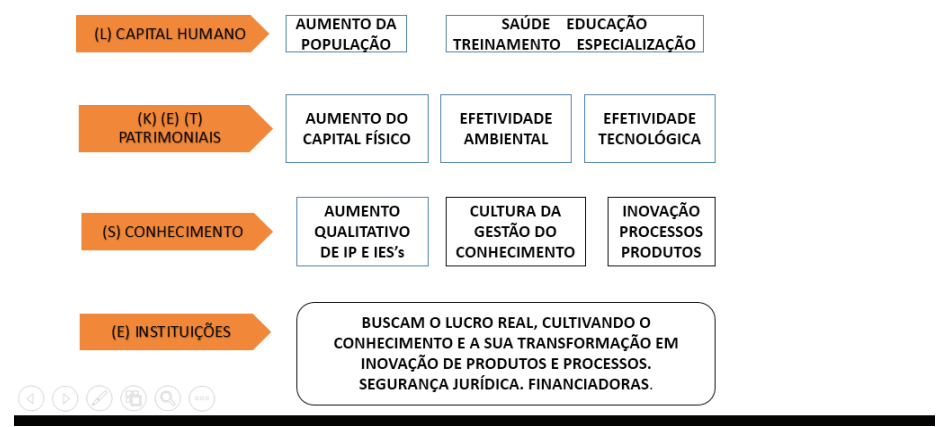

Figura 4. Modelo da Nova Teoria do Crescimento Econômico

Fonte: Elaborado pelos autores. 


\section{A Insegurança Jurídica do Brasil}

Muitos estudos têm demonstrado o quanto a Insegurança Jurídica tem em muito prejudicado o crescimento econômico brasileiro. O prêmio Nobel de Economia em 1993, Douglass North, já indicava o Brasil como um país prejudicado no seu crescimento econômico causado pela insegurança jurídica.

A mais simples forma desta confirmação é como vimos no título anterior que o crescimento econômico depende do aumento qualitativo e quantitativo dos fatores de produção, e dentre eles o estoque de conhecimento, recurso decisivo para ou aumento do PIB per capita, pois ele é a matéria prima para a inovação, única condição do crescimento do PIB per capita real.

A inovação de acordo com a teoria neo-schumpeteriana, é o conhecimento que gera lucro, e para que ocorra, são necessários conhecimento, empresários empreendedores e banqueiros que não temem o risco. Os banqueiros podem ser substituídos pelo lucro puro ou real.

Neste novo ciclo econômico, o ciclo do conhecimento, é a inovação que explica a distância das Naçóes ricas e pobres, ou seja, as desenvolvidas das subdesenvolvidas per capita.

Os países ricos com estoque inicial de conhecimento maior crescerão mais do que os países pobres, porque cada unidade capital investido aumenta tanto o estoque de capital físico, como o nível de tecnologia da economia e a produtividade marginal do capital. Além disso, as diferenças de tecnologia tendem a gerar importantes economias externas nas regiōes dos países ricos, gerando efeitos desfavoráveis nos países e regiōes pobres (ROMER, 1994, p.7 e 9).

Para o aumento de qualquer fator de produção, é necessário investimento que só é possível quando existe poupança, não existe nenhuma maneira conhecida até hoje, de investir sem que ocorra a poupança. Como é fundamental o investimento para que ocorra o Crescimento Econômico, importante saber como obtê-lo. É através da poupança que ocorre com um sacrifício de uma necessidade no presente para a produção de mais bens econômicos no futuro, desde que este sacrifício seja investido em fatores de produção, que com seu aumento fará crescer a produção de bens econômicos de consumo no futuro.

Mas o tamanho do sacrifício no presente muda de Nação para Nação, em função de muitas variáveis, entre elas as culturais, as intelectuais, da quantidade de fatores de produção já acumulados na sua história, o estoque de conhecimentos e o amadurecimento das Instituiçôes. Outras variáveis como saúde, educação, segurança são também importantes para gerar poupança. A relação do que é produzido e a quantidade de necessidades a serem atendidas também são fatores importantes para a poupança, pois se a produção é pequena em relação às necessidades de um povo, mais difícil fica o ato de poupar. 
Para produzir novos fatores, qualificá-los e inová-los, é preciso consumir menores quantidades no presente a fim de consumir melhores no futuro; e a poupança é a única condição para o crescimento. Pela importância do conceito científico, vale tomar como exemplo toda a produção de um país (PIB), como sendo um saco de arroz; neste caso, a única forma de crescimento é transformar parte do saco de arroz em sementes (fator de produção) para o plantio (o não consumido foi poupado). O restante pode-se consumir ou exportar (bens de consumo). Quanto maior a poupança (sementes para o plantio) maior o investimento (plantio de sementes) e maior será o crescimento econômico (ALMEIDA, 2009, p. 14).

A importância da segurança jurídica para o ato de poupar e investir fica tácita no exemplo acima, pois as pessoas só farão sacrifício no presente na certeza do benefício no futuro. Sem esta certeza a poupança tende a não existir e quando existe irá procurar investir onde ocorre a garantia jurídica dos valores definidos pelo mercado, como a garantia da propriedade privada, da liberdade de escolha, da não intervenção do Estado, enfim, de um ambiente onde os contratos sejam respeitados no presente e futuro.

O Estado de Direito é a condição para que ocorra investimento, principalmente o investimento intensivo e de alto risco como a inovação.

No Estado de Direito, porém, a segurança jurídica não decorre apenas da estabilidade, certeza, previsibilidade e calculabilidade do ordenamento jurídico positivo, mas também do respeito a esses preceitos gerais na sua interpretação e aplicação pelo Judiciário. Mais especificamente, a segurança jurídica requer que esses preceitos sejam respeitados em quatro dimensóes da atuação de Justiça (PINHEIRO, 2005, p.3).

Mas a poupança inteligente, a poupança geradora do investimento em inovação, representa altos valores e dispostos a altos riscos, para tal as necessidades das garantias jurídicas, como também de legislaçóes hodiernas que facilitem as exportaçôes, pois para ocorrer o lucro real, são necessários muitos consumidores, e estes se encontram além das fronteiras geopolíticas da localização das unidades produtoras.

Armando Pinheiro evidencia que a insegurança jurídica dificulta as relaçóes econômicas, porque as bases onde se calcam ficam instáveis; os seus efeitos, mais difíceis de prever, e os custos e benefícios, mais complicados de calcular. E continua dizendo que existem três reaçôes possíveis a essas incertezas, todas elas implicando sacrifício da eficiência econômica, seja na não realizar as transaçóes que têm alto nível de risco, abrindo-se mão dos ganhos que elas poderiam gerar; ou realizá-las de outra forma, reduzindo apenas parcialmente o ganho obtido, ou ainda, compensar a baixa segurança com o uso mais intenso das instituições jurídicas disponíveis, consumindo mais recursos no atividades-meio.

O empreendedor investidor considera a segurança jurídica de um país com o enfoque da definiçãao e de proteção dos direitos de propriedade e os custos de transação. 
Como afirma Pinheiro (2005), o papel do Estado é assinalar e proteger os direitos de propriedade que é habilidade de se dispor de maneira absoluta, no todo ou em parte, dos bens que possui, ou dos serviços e benefícios que elas podem produzir, desde que sem conflitar com o que é proibido pela legislação.

Os custos de transação estudada por Coases, ganhador do prêmio Nobel de Economia de 1991, observa que estes custos estão para a Economia como o atrito está para a Física: quanto maiores forem mais esforço precisará ser realizado para se obter o mesmo resultado.

De forma a realizar uma transação no mercado é necessário descobrir com quem se quer transacionar, informar às pessoas que se quer negociar e em que termos, conduzir negociações que levem a um acordo, redigir um contrato, monitorar o seu cumprimento de forma que os seus termos estão sendo respeitados, e assim por diante (COASE, 1988).

Pinheiro (2005), diz que além da presença de direitos de propriedade bem-definidos, a melhor maneira de o direito estimular a eficiência econômica é reduzindo os custos de transação. E continua afirmando que, essa é, claramente, uma das funçôes da segurança jurídica, na medida em que ela reduz os custos incorridos em "redigir um contrato e monitorar o seu cumprimento de forma a garantir que os seus termos estáo sendo respeitados". Considerem-se, separadamente, essas duas etapas: ex-ante, a redação do contrato, e, ex-post, se e quando sua execução for colocada em risco.

Como dito, vários são os motivos de um contrato não completo, como no caso de alguns dos riscos da transação não são explicitados no contrato, é neste momento que é importante a segurança jurídica, através de uma jurisprudência estável e previsível que, de um lado ajude as partes a remediar o contrato e, do outro, facilite a obtenção de uma solução para o conflito sem necessidade de recurso ao Judiciário. E Pinheiro (2005, p. 7), cita Gorga (2005) sobre a doutrina do stare decisis:

"[A] natureza de bem público do precedente fará com que terceiros se beneficiem do precedente sem terem para isso gasto recursos em processos judiciais". Assim, nos próximos litígios, a existência de precedente eficiente induzirá a que as partes não entrem em conflito judicial, já que o precedente, com diz Barzel, tem a funçáo de delinear direitos (de propriedade). As partes, sabendo do precedente, poderão resolver seus conflitos fora da corte (settlement), adotando as definiçôes manifestadas no precedente.

Um país, como o Brasil, que não tem uma jurisprudência coerente, constante e previsível, a efetividade econômica (eficiência mais eficácia), será comprometido em função da maioria dos recursos produtivos serem escassos. Os custos de um litígio consomem muitos recursos que são desviados da produção para ser direcionados para advogados, 
para o tempo e atenção das partes, para o aparelhamento de um Judiciário, pois são serviços altamente especializados, que utilizam de recursos desviados da produção de bens e serviços.

A falta de previsibilidade normativa estimula o uso indevido dos tribunais. $\mathrm{Na}$ ausência de uma jurisprudência bem estabelecida, os magistrados podem se ver às voltas com enorme carga de trabalho, pois cada caso terá que ser julgado individualmente, havendo incentivos fortes, para que todos os conflitos sejam levados à apreciação da Justiça, em vez de serem resolvidos entre as partes. Portanto, a jurisprudência, devidamente pacificada, dá agilidade aos tribunais, reduzindo a carga de trabalho resultante das demandas repetitivas e liberando os magistrados para se dedicarem a casos singulares (PINHEIRO, 2005, p. 8).

O Brasil, nesta primeira quinzena do século XXI, comprova esta afirmação de Pinheiro (2005), o que resulta em um Judiciário moroso, ineficiente e ineficaz, o que consolida a insegurança jurídica de nosso país. A consequência é um país com os juros, os preços dos bens e serviços econômicos elevados, para pagar os custos da insegurança jurídica.

O resultado é uma distorção do sistema de preços e juros, brasileiros, que diminui a eficiência da utilização dos recursos produtivos e compromete todo o desempenho da economia nacional, dificultando em muito a possibilidade de vencer a concorrência internacional de países com estabilidade e segurança jurídica.

Outro fator que contribui para a insegurança jurídica no Brasil é sua morosidade. De acordo com Castelar, quando participava do ciclo de debates "Justiça e Economia" promovida em 2007 pelo Instituto Brasileiro de Ética Concorrencial - ETCO, afirmou que a maioria dos julgamentos no Brasil é desnecessária, pois se refere à mesma causa. Continua dizendo que a metade $(58 \%)$ dos mais de 100 mil processos que havia em 2007 em trâmite no Supremo Tribunal Federal (STF) tratavam de apenas 45 temas. Um levantamento do Superior Tribunal de Justiça (STJ), na mesma época indicava que 62\% dos processos têm a Caixa Econômica Federal, o INSS e a União como parte e termina afirmando que uma mesma causa é julgada dezenas e milhares de vezes no Brasil. Para Castelar, a maior parte desses casos deveria passar a ser resolvida na primeira instância, especialmente aqueles que já tiveram decisões semelhantes, uma vez que se trata de jurisprudência pacificada (ETCO, 2008).

Pesa também na insegurança jurídica brasileira, a maneira em que os juízes tomam suas decisóes. Como entendem o poder Judiciário na solução dos conflitos. Quem deve ser protegido e quem deve ser penalizado, independente da definição legal.

O maior peso desse custo Brasil está na predominância das decisōes judiciais consequencialistas sobre os formalistas. As primeiras consideram as consequências sociais, políticas e econômicas de suas decisóes, na sua pessoal visão ideológica, religiosa e política. 
Já os formalistas dão valor à coerência formal de suas decisōes em relação ao texto da lei. Não se consideram responsáveis pelas consequências práticas da sentença, pois entendem que o responsável para fazer leis e suas consequências é o Poder Legislativo (ALMEIDA, 2012, p. 311).

No encontro ETCO citado, Castelar apresentou uma pesquisa que realizou em 2003, em parceria do cientista político Bolívar Lamounier e a Professora Maria Tereza Sadek, a qual demonstra que $80 \%$ dos magistrados disseram que o juiz tem papel social, mesmo ao custo de violar contratos. Do ponto de vista da segurança jurídica, afirma Castelar, "é problemático que as instituiçóes em tese encarregadas de defender a segurança jurídica sejam aquelas que menos acreditam que esse é seu papel principal” (ETCO, 2008).

\section{Conclusões}

Considerando que o Crescimento Econômico per capita de um país só ocorre contemporaneamente com o aumento dos fatores de produçáo, notadamente com o aumento do estoque de conhecimento;

Considerando que a nova teoria do crescimento econômico per capita, elege a inovaçáo como o fator de gerador de produçáo de bens e serviços em uma velocidade que compensa os rendimentos decrescentes dos outros fatores (PARKIN, 2009);

Considerando que a nova teoria, diferente da teoria malthusiana, acredita que uma população maior leva a mais necessidades, mas também a mais descobertas científicas e avanços tecnológicos. Assim, em vez de ser uma fonte de redução do PIB real per capita, o crescimento populacional leva ao crescimento mais rápido da produtividade e a um PIB per capita crescente. Os recursos são limitados, mas a imaginação e a capacidade humana de aumentar a produtividade são ilimitadas (PARKIN, 2009);

Considerando que essa teoria é estimulada pelo aumento das necessidades humanas, nacionais e internacionais, justificando a importância de infraestruturas modernas e políticas econômicas que estimulem as exportaçóes;

Considerando que a inovação é resultado de empreendedores inovadores (resultado de investimentos na cultura e educaçáo), de estoque de conhecimento (resultado investimentos em Universidades e Institutos de Pesquisa) e abundância de capital de alto risco e de longo prazo (resultado de estímulo a poupança destemida e lucros reais);

Considerando a inovação o diferencial dos países desenvolvidos e subdesenvolvidos na era do conhecimento;

Considerando que, para ampliar os recursos produtivos, é necessário o investimento nestes fatores; 
Considerando que o investimento só ocorre se existir poupança;

Considerando que o Brasil não tem poupança suficiente para o aumento dos fatores, principalmente do fator conhecimento, matéria prima da inovação;

Para o Brasil caminhar para ser desenvolvido tem necessariamente que atrair a poupança internacional ou poupança de brasileiros que estão no exterior, para o investimento em recursos produtivos e infraestrutura.

Esta poupança aplicada em investimentos de longo prazo na produção de bens econômicos agregados com inovação, só irá para países onde ocorre "segurança jurídica", que não é o caso do Brasil hodierno.

Nossa proposta é criar uma zona livre do direito público brasileiro, onde os agentes econômicos públicos e privados teriam a liberdade de arbitrar pela justiça privada através a arbitragem ou da justiça pública do país em que sentiria maior segurança jurídica para seus contratos.

A “Zona Livre de Arbitragem” implantada na Regiáo Metropolitana da Baixada Santista, pelas suas qualificações atuais: do maior porto marítimo brasileiro, pelo polo de inovação na área de tecnologia, pelo polo industrial de Cubatão e pela sua posição geoeconômica e geopolítica.

Claro que uma proposta deste porte terá que passar pelo Congresso Nacional, mas não será novidade, se associarmos à Zona Franca de Manaus que foi criada pelo Decreto-Lei $288 / 1967$.

Através de uma política jurídica e econômica, com inovação, para o Brasil desta quinzena do século XXI é que poderemos deixar de ser um país subdesenvolvido e viver o estágio de um país desenvolvido nas próximas geraçoes, onde as diferenças deixaráo de ser geopolíticas para serem geomentais, e as mentes que gerarem mais inovação serão as que irão contemplar as necessidades das geraçôes futuras.

\section{Referências}

ALMEIDA, L. C. B. Introdução ao Direito Econômico. 4a . Ed.. São Paulo: Saraiva, 2012.

ALMEIDA, L. C. B. Custo Brasil x (IN) Segurança Jurídica. Revista Jurídica Consulex. Brasília. Ano XIII - n. 306, p. 14-15, 15 out. 2009.

BANCO MUNDIAL. Relatório sobre desenvolvimento mundial 2012. Washington: Banco Mundial, 2013.

COSTA, F. N. O Profeta da Inovação: Joseph Schumpeter e a Destruição Criativa. Posted on 23/12/2012. Disponível em: <https://fernandonogueiracosta.wordpress. 
com/2012/12/23/o-profeta-da-inovacao-joseph-schumpeter-e-a-destruicao-criativa-2/>. Acesso em: 15 de jan. 2015.

DORSI, G. Sources, procedurs and microeconomic effects of innovations. Journal of Economic Literature, v. XXVI, p. 1120-1171, sept. 1988.

ETCO - Instituto Brasileiro Concorrencial. Direito e Economia. São Paulo: Saraiva, 2008.

FMI - International Monetary Fund (2013). PIB per capita. Washington: FMI, 2014. Disponível em: <http://en.wikipedia.org/wiki/List_of_countries_by_ GDP_\%28PPP\%29_per_capita>. Acesso em: 14 de jan. 2015.

HUGON, P. História das doutrinas econômicas. São Paulo: Atlas, 1995.

OCDE: Manual de Oslo: Proposta de Diretrizes para Coleta e Interpretação de Dados sobre Inovação Tecnológica, 3. Ed. 2005 (traduzido para o português pela FINEP).

NORTH, C. D. Institutions, Institutional Change and Economic Performance. Cambridge: Cambridge University Press, 1990.

NUSDEO, Fabio. Curso de economia: introdução ao Direito Econômico. São Paulo: RT, 2008.

PARKIN, M. Economia. 8. ed. São Paulo: Addison Wesley \& Pearson, 2009.

Pereira, R.S.et al. O ensino da "inovação" na administração, ciências contábeis, turismo e tecnologia em gestáo: um estudo exploratório em instituiçóes de ensino superior brasileiras. Revista de Administração e Inovação, São Paulo. v.9 n.4, p.221-224, out-dez. 2012.

PINHEIRO, A.C. Segurança Jurídica, Crescimento e Exportaçóes. Instituto de Pesquisa Económica Aplicada - IPEA 2005 COMITÉ 22 IPEA texto para discussão | 1125 | out2005.

ROMER, P. M. Increasing returns and long-run growth. Journal of Political Economy, v. 94, n.5, 1986.

SCHUMPETER. Joseph Alois. Teoria do Desenvolvimento Econômico Uma Investigaçáo Sobre Lucros, Capital, Crédito, Juro E O Ciclo Econômico. Tradução de Maria Sílvia Possas. Sao Paulo: Editora Nova Cultural Ltda, 1997.

SUZIGAN, W. ; ALBUQUERQUE, E.M.; CAIRO. S.A.F. (org.). Em busca da inovação: interação universidade-empresa no Brasil. Belo Horizonte: Autêntica, 2011. 